\title{
Elaboración de bebida energizante a partir de suero de quesería
}

\author{
Cuellas, A. ${ }^{(1)}$, Wagner, J. (1) \\ (1) Universidad Nacional de Quilmes, Buenos Aires, Argentina. \\ Contacto: acuellas@unq.edu.ar \\ Recibido: 20/05/2010 - Aprobado: 15/09/2010
}

\begin{abstract}
$\underline{\text { Resumen }}$
Se estudió la factibilidad para elaborar diferentes productos a partir de suero de queso. Los resultados mostraron que el desarrollo de una bebida energizante representa un proceso simple para obtener productos de alto valor agregado y utiliza todos los componentes del suero lácteo. Experimentalmente, se hidrolizó la lactosa presente al $80 \%$ y se formularon bebidas frutales. Éstas fueron evaluadas mediante pruebas sensoriales descriptivas, mostrando mejores características organolépticas para la bebida sabor naranja. Los análisis microbiológicos realizados en la bebida láctea se ajustaron a los valores solicitados por el Código Alimentario Argentino para leches UAT. Se concluye que la elaboración del producto no presenta dificultades tecnológicas, reduce la contaminación ambiental y aprovecha el valor nutricional del efluente. Palabras clave: Efluente, industria láctea, hidrólisis, lactosa.
\end{abstract}

\begin{abstract}
The feasibility to elaborate different products from whey of cheese was studied. The results showed that the development of an energy drink represents a simple process to obtain products of high added value and uses all serum components. Experimentally, the lactose was hydrolyzed to $80 \%$ and fruit drinks were made. These were evaluated by descriptive sensory tests, showing better organoleptic characteristics for orange-flavored drink. The microbiological analyses carried out in the milk drink were consistent with the values requested by the Argentine Food Code for milk UHT milk. We conclude that the development of the product has not technological difficulties, reduce environmental pollution and takes advantage of the nutritional value of the effluent.

Kevwords: Effluent, dairy, hydrolysis, lactose.
\end{abstract}

\section{Introducción}

La industria quesera produce grandes volúmenes de suero lácteo, único subproducto remanente en el proceso de elaboración. Por cada $\mathrm{kg}$ de queso, se producen aproximadamente 9 litros de efluente, desechado casi en su totalidad, incrementando los niveles de contaminación (Cuellas, 2008; Miranda, 2007; González-Martínez et al., 2002). Por otro lado, el suero lácteo posee un alto valor nutritivo, contiene más del $50 \%$ de los sólidos de la leche, incluyendo proteínas, lactosa, minerales y vitaminas (Atra et al., 2005; Smithers, 2008). El poder contaminante del suero lácteo y su atractivo valor nutricional han impulsado investigaciones que permitan su empleo en el desarrollo de ingredientes y productos alimenticios. Sin embargo, el pequeño y mediano productor quesero no dispone de recursos ni de equipos industriales para el tratamiento del efluente (Monsalve y González, 2005).

El lactosuero está constituido principalmente por lactosa, un azúcar relativamente insoluble, de bajo poder edulcorante, que no siempre puede ser absorbida por el sistema digestivo humano. De esta forma la hidrólisis de la lactosa es de vital importancia para el empleo del efluente en la industria alimenticia, ya que produce glucosa y galactosa, una mezcla que presenta mayor solubilidad, mayor poder edulcorante y es de fácil absorción por la mucosa digestiva (Zadow, 1984; Barnes, 1994; Cuellas, 2005).

Las características y composición del efluente permiten diseñar un abanico de opciones para el desarrollo de productos alimenticios. El criterio de selección para la elaboración de algunos de estos productos debe adecuarse a las necesidades y posibilidades de los establecimientos queseros y considerar aspectos fundamentales, como el costo del proceso, el tiempo de producción y la posibilidad de ingresar el producto obtenido en el mercado.

Este trabajo incluye un estudio de factibilidad para la elaboración de distintos productos en base a suero de quesería y una segunda etapa experimental en la que se desarrolla la formulación del producto seleccionado.

\section{Materiales y Métodos}

\section{Estudio de pre-factibilidad para la elaboración de productos a partir del suero}

En el estudio de factibilidad se incluye el análisis de aspectos considerados fundamentales para la elaboración de productos alimenticios a partir del suero, como: nivel de aprovechamiento, tiempo y costo de producción, reducción de contaminación y aceptación para distintos productos (Ricotta, Concentrado proteico, quesos tipo Mysost y bebidas).

\section{Desarrollo del producto}


Obtención de jarabes de lactosa con distintos grados de hidrólisis: La bebida se formuló en base a suero de queso en polvo sin desmineralizar (Lácteos Vidal S.A), reconstituido al 5\% p/v de lactosa, tal como se encuentra naturalmente en el efluente. La hidrólisis enzimática de lactosa se realizó en Batch por acción de la enzima $\beta$-galactosidasa (Lactozym 30001 Novo Nordisk) a $37^{\circ} \mathrm{C}$, pH 6.8-7 y se frenó con la adición de acido cítrico, hasta alcanzar $\mathrm{pH} 4$. Dependiendo del tiempo de contacto de la enzima con el suero lácteo, se obtuvieron hidrolizados de lactosa de $20 \%, 50 \%$ y $80 \%$. El grado de hidrólisis se determinó midiendo la concentración de glucosa liberada por dosaje enzimático mediante un kit de glucemia (Wiener Lab.), midiendo la absorbancia a $505 \mathrm{~nm}$ y comparando con un estándar.

La reacción calorimétrica sigue el siguiente esquema:

Glucosa $+\mathrm{O}_{2}+\mathrm{H}_{2} \mathrm{O}$ GOD ácido glucónico $+\mathrm{H}_{2} \mathrm{O}_{2}$

$2 \mathrm{H}_{2} \mathrm{O}_{2}+4-\mathrm{AF}+\mathrm{Fenol} \longrightarrow \mathrm{POD} \longrightarrow 4$ (p-benzoquinona-monoimino $)+4 \mathrm{H}_{2} \mathrm{O}$

Donde: GOD/POD: Solución de glucosa-oxida (1000 U/ml) y peroxidasa $(120 \mathrm{U} / \mathrm{ml})$

Reactivo 4-AF: Solución de 4-aminofenazona $25 \mathrm{mmol} / \mathrm{l}$ en buffer TRIS $0,92 \mathrm{~mol} / \mathrm{l}$.

Formulación de la bebida: Luego de determinar que el suero hidrolizado al $80 \%$ presenta mejores aptitudes para la elaboración del producto, se formularon bebidas en base a este jarabe, adicionando benzoato de sodio, sacarosa y mezclas aditivas (saborizante y colorante) de naranja (formulación I), pomelo (formulación II) y frutilla (formulación III)

Evaluación de las características organolépticas a partir de panel sensorial: La evaluación de la magnitud de los atributos sensoriales (aroma, color, sabor y consistencia) de las bebidas formuladas se realizó mediante pruebas sensoriales descriptivas, empleando una escala estructurada de tres puntos (Débil-MedioBueno). Para tal fin se entrenó un panel de 20 jueces, conformado por estudiantes y docentes de la Universidad Nacional de Quilmes.

Análisis microbiológicos: La bebida formulada se somete a los siguientes controles microbiológicos: Recuento de Coliformes totales a $30{ }^{\circ} \mathrm{C}$ - NMP (ICMSF, 2000). Recuento de Coliformes Fecales y E. Coli. Recuento de Mesófilos Totales (ICMSF, 1983). Recuento de S. Aureus (Met. 975.55 AOAC 1995). Estos controles se realizan al finalizar el proceso de elaboración a escala laboratorio, se almacena el producto a $4-5^{\circ} \mathrm{C}$ y se repiten los análisis en los días 15 y 30 . Todos los ensayos microbiológicos se realizaron por triplicado.

\section{Resultados y Discusión}

\section{Estudio de pre-factibilidad para la elaboración de productos a partir del suero de quesería:}

De acuerdo a las características de las opciones analizadas (Tabla 1), se ha determinado que el producto que presenta mayores ventajas y mayor oportunidad de aceptación es la bebida en base a suero lácteo. Productos similares como bebidas isotónicas y energizantes responden a la nueva tendencia de consumo de alimentos naturales y funcionales, constituyendo un mercado en expansión. Por otro lado, el proceso de elaboración de la bebida utiliza de forma integral los recursos, emplea una tecnología sencilla de implementar y reduce casi en su totalidad el impacto ambiental generado por este efluente (Inda Cunningham, 2000).

\begin{tabular}{|c|c|c|c|c|}
\hline Producto & $\begin{array}{c}\text { Nivel de } \\
\text { aprovechamiento }\end{array}$ & $\begin{array}{c}\text { Tiempo y costo } \\
\text { de producción }\end{array}$ & $\begin{array}{c}\text { Reducción de } \\
\text { contaminación }\end{array}$ & $\begin{array}{c}\text { Aceptabilidad } \\
\text { del producto }\end{array}$ \\
\hline Ricotta & Medio - bajo & Mediano & Bajo & Mediana \\
\hline $\begin{array}{c}\text { Concentrado } \\
\text { proteico }\end{array}$ & Medio - bajo & Alto & Bajo & Alta \\
\hline $\begin{array}{c}\text { Queso tipo } \\
\text { Mysot }\end{array}$ & Alto & Mediano & Alta & Baja \\
\hline $\begin{array}{c}\text { Bebida } \\
\text { Isotónica }\end{array}$ & Alto & Bajo & Alta & Alta \\
\hline
\end{tabular}

Tabla 1. Análisis de pre-factibilidad de productos elaborados en base a suero de quesería.

\section{Desarrollo del producto}

Determinación del grado de hidrólisis: La elección del jarabe que se utilizó como base en la formulación se relacionó con la cantidad necesaria de sacarosa que se debe adicionar al producto final para conferirle un sabor dulce. Las bebidas formuladas con sueros hidrolizados al $80 \%, 50 \%$ y $20 \%$ de conversión de la lactosa tendrán composición constante en todos los ingredientes menos en sacarosa, que requerirá una adición baja, media y alta, respectivamente. Teniendo en cuenta la solubilidad, el poder edulcorante y la digestibilidad de los azúcares, a mayor grado de hidrólisis la bebida presentará ventajas nutricionales y tecnológicas, por contener una mayor proporción de monosacáridos y menor sacarosa y lactosa (lo que favorece la rápida absorción y una menor respuesta insulínica) y un menor costo de producción.

\section{Evaluación sensorial}

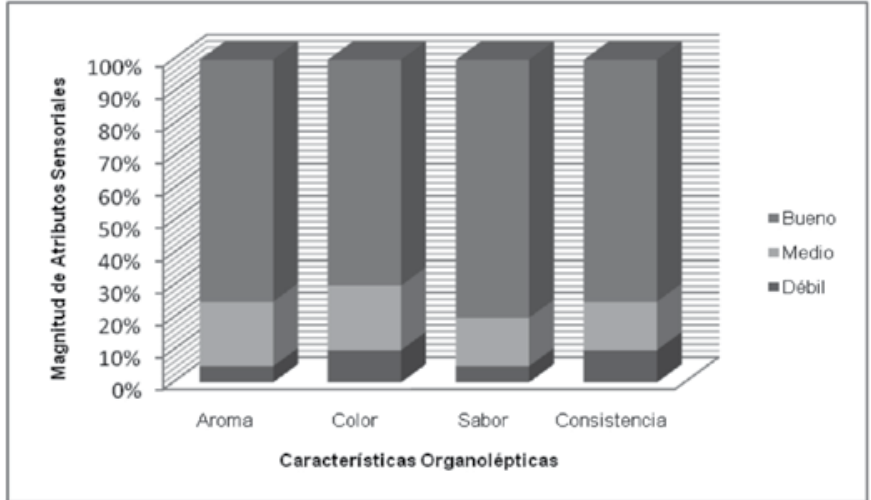

Gráfico 1. Evaluación sensorial descriptiva de bebida láctea sabor naranja formulada a partir de suero hidrolizado al $80 \%$.

En los Gráficos 1, 2 y 3 se muestran los resultados del estudio 
organoléptico descriptivo sobre las características sensoriales de las tres bebidas formuladas (naranja, pomelo, frutilla) a partir de lactosuero hidrolizado al $80 \%$. Estos ensayos, además de caracterizar los atributos sensoriales, describen la intensidad de los mismos, mostrando una evaluación favorable de las propiedades sensoriales de los sabores cítricos (naranja y pomelo) en bebidas isotónicas. Por su parte, el panel describió mejores características referentes al color y al aroma en la bebida de naranja, por lo que se decidió incorporar este sabor en la formulación final del producto.

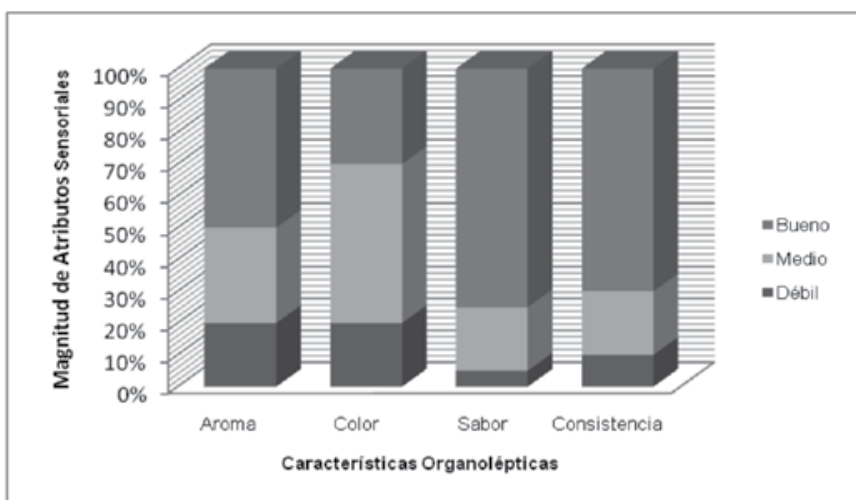

Gráfico 2. Evaluación sensorial descriptiva de bebida láctea sabor pomelo formulada a partir de suero hidrolizado al $80 \%$.

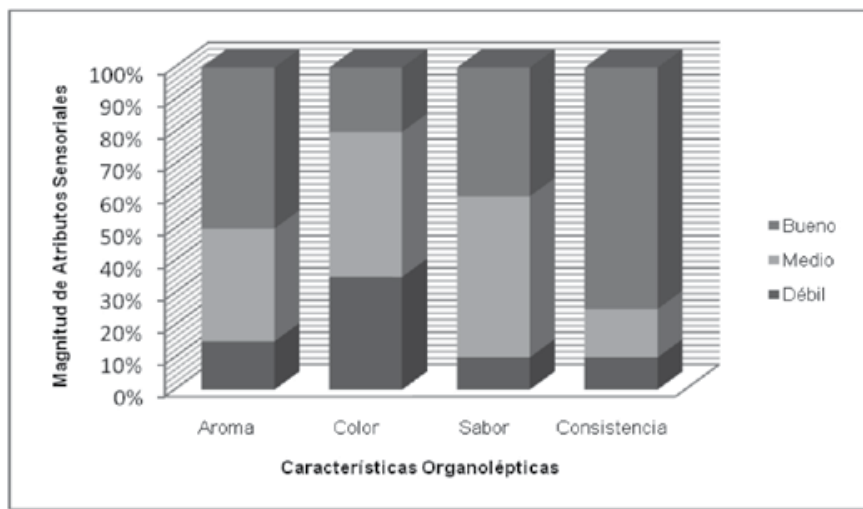

Gráfico 3. Evaluación sensorial descriptiva de bebida láctea sabor frutilla formulada a partir de suero hidrolizado al $80 \%$.

Formulación final y características del producto obtenido: Los estudios realizados conducen a la formulación de una bebida láctea hidrolizada sabor naranja de $\mathrm{pH}$ ácido, que posee un proceso de elaboración sencillo (Gráfico 4). La composición nutricional cada 100 $\mathrm{ml}$ de producto incluye $13 \mathrm{~g}$ de hidratos de carbonos, $1 \mathrm{~g}$ de proteínas, $54 \mathrm{mg}$ de sodio y $1.5 \mathrm{mg}$ de otros minerales, representando un aporte de $56 \mathrm{kcal}$. Por su contenido de sales e hidratos de carbono se clasifica como bebida isotónica.

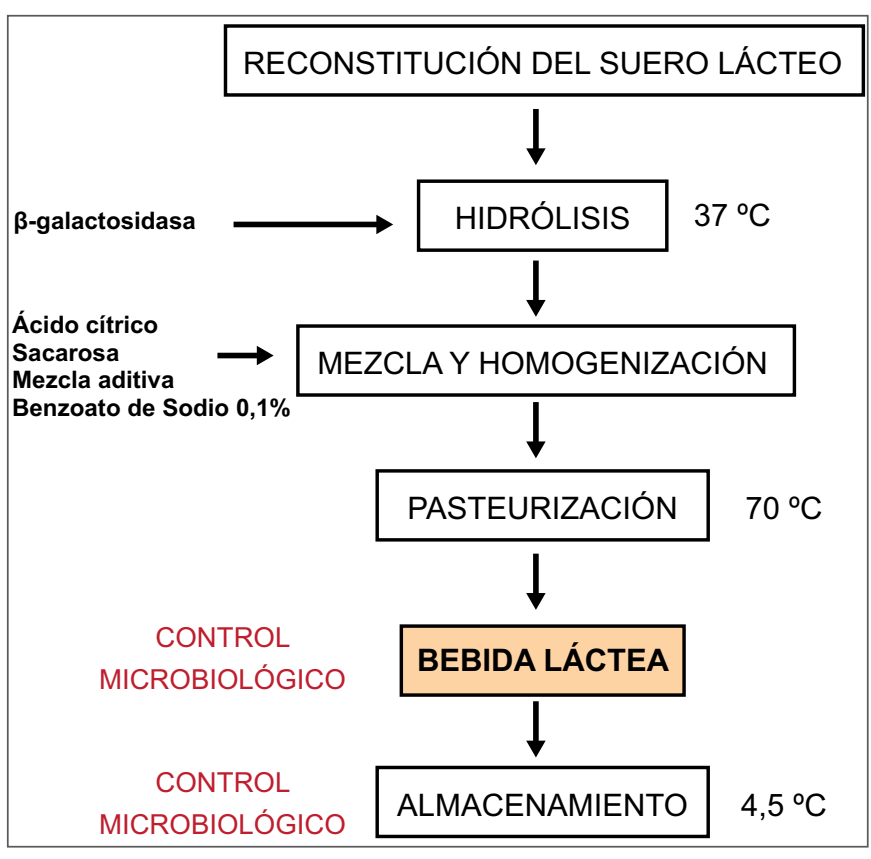

Gráfico 4. Diagrama de flujo del proceso de elaboración de bebida láctea en base a suero lácteo en escala laboratorio.

Resultados microbiológicos: Coniformes Totales: NMP $<3$ / Coliformes Fecales: Ausencia / E. Coli: Ausencia / Recuento de Mesófilos Totales $<10 \mathrm{UFC} / \mathrm{ml} /$ S. Aureus: Ausencia (para todas las muestras analizadas), estos valores se ajustan a los solicitados por el Código Alimentario Argentino para leches UAT.

\section{Conclusiones}

En las formulaciones realizadas se obtuvo una bebida isotónica altamente aceptada por un panel sensorial, de buenas características organolépticas y amplias posibilidades de inserción en el mercado. El proceso de elaboración no presenta dificultades tecnológicas, requiere instalaciones de uso común en la industria láctea y permite que los productores de queso reduzcan el impacto ambiental que ocasiona la mala disposición del suero. Considerando que en el desarrollo industrial de los países de la región es fundamental implementar sistemas de gestión que conjuguen el aprovechamiento integral de los recursos y minimicen la contaminación del ambiente, se concluye que la elaboración de este producto posibilita llevar a cabo procesos más eficientes, tecnologías más limpias y mayor rentabilidad.

\section{Referencias}

- AOAC INTERNATIONAL. Official Methods of Analysis International. 16th. ed. Gaithersburg: AOAC, 1995. Official Method 975.55.

- ARGENTINA. MINISTERIO DE SALUD. Código alimentario argentino. Cap. VIII. Buenos Aires: ANMAT, 2006.

- ATRA, R.; VATAI, G.; BEKASSY-MOLNAR, E.; BALINT, A. Investigation of ultra-and nanofiltration for utilization of whey protein and lactose. En: Journal of Food Engineering. 2005, 67(3):325-332.

- BARNES, Lewis. Manual en nutrición en pediatría. 3a. ed. Buenos Aires: Editorial Médica Panamericana, 1994.

- CUELLAS, Anahí. Aprovechamiento industrial del suero de 
quesería. Obtención de una bebida energizante a partir del efluente. En: Tecnología Láctea Latinoamericana. 2008, (49):56-58.

- CUELLAS, Anahí. Estudio de un reactor con enzimas inmovilizadas para el procesamiento de suero de quesería. Santa Fe: Universidad Nacional del Litoral, 2005. (Tesis de Maestría).

- GONZÁlEZ-MARTÍNEZ, C.; BECERRA, M.; CHÁFER, M.; ALBORS, A.; CAROT, J.M.; CHIRALT, A. Influence of substituting milk powder for whey powder on yoghurt quality. En: Trends in Food Science \& Technology. 2002, 13(9-10):334-240.

- INDA CUNNINGHAM, Arturo Enrique. Optimización del rendimiento y aprovechamiento en la industria de quesería. Cap. 4. México: OEA, 2000. pp. 63-93.

- INTERNATIONAL COMmISSION ON MICROBIOLOGICAL, SPECIFICATIONS FOR FOODS (ICMSF). Microorganismos en los alimentos, 1: su significado y los métodos de enumeración. 2.ed. Zaragoza: Acribia, 2000.

- INTERNATIONAL COMmISSION ON MICROBIOLOGICAL, SPECIFICATIONS FOR FOODS (ICMSF). Microorganismos de los alimentos 1: técnicas de análisis microbiológico. Zaragoza: Acribia, 1983.

- MIRANDA, Oscar. Elaboración de una bebida fermentada a partir del suero de queso. Características distintivas y control de calidad. En: Revista Cubana Alimentación y Nutrición. 2007, 17(2):103108.

- MONSALVE, Jorge; GONZÁLEZ, Danelis. Elaboración de un queso tipo Ricotta a partir de suero lácteo y leche fluida. En: Revista Científica. 2005, XV(6):543-550.

- SMITHERS, Geoffrey W. Whey and whey proteins. From 'gutterto-gold'. En: International Dairy Journal. 2008, 18(7):695-704.

- ZADOW, J. Lactose: properties and uses. En: Journal of Dairy Science. 1984, 67(11):2655-2679. 